\title{
Faculty Perceptions Of Resource Constraints In Business Academic Research
}

Douglas P. Dotterweich (E-mail: dotterwe@etsu.edu), East Tennessee State University Sharon Garrison, University of Arizona

\begin{abstract}
Administrators and faculty are grappling with the relative importance of teaching and research by professors in higher education. While various opinions exist, both faculty and administrators will likely agree that research will remain prominent in the near future. Faculty frustration can result from inadequate support for research. A national survey of business school faculty examines support adequacy by type of school. Of the ten categories of research support studied, six are receiving less than adequate support. Administrators who allocate their limited research budgets based on the findings of this study will likely remove many of the obstacles their faculty members face in meeting the research objectives of their institutions.
\end{abstract}

\section{Introduction}

n recent years, higher education seems torn in several different directions. At some institutions, multiyear appointments have replaced tenure. At others, technological advances are being viewed as possible substitutes for traditional modes of teaching. Some faculty and unions decry such moves as attempts to replace the professorate. There are efforts to focus the attention of professors on teaching and service rather than research, and attempts to emphasize more basic research. At the same time, some institutions are engaged in bidding wars for the services of top scholars. In such an environment, obtaining a more complete understanding of resource availability and resulting motivations for pursuing scholarship is an important issue in higher education.

Those variables leading to scholarly productivity have been studied by a number of authors. An anonymous article in [Change, 1991] used support for faculty research to rank institutions on a research-intensive continuum.

[Tien and Blackburn, 1996] tested intrinsic and extrinsic psychological motivations for scholarly productivity and promotion in rank by use of behavioral reinforcement and selection function theory. Basically, behavioral reinforcement theory postulates that promotion has a motivating effect on faculty research performance. Selection function implies productivity differences between promoted and non-promoted faculty. The authors do not find full support for either notion; although they point out that intrinsic as well as extrinsic factors are important research motivators.

[Kraemer and Perry, 1989] offer four types of support that are important for research stimulus.

1. Institutional values that support research. These would include research performance, appropriate teaching loads, release time from teaching for research, and awards and recognition for research performance.

2. Faculty capable of performing research. This may require recruiting faculty from Ph.D. programs where research methods and practice are taught in the doctoral curriculum.

3. Research resources.

4. Institutionalization of the research effort. 
At the same time however, many authors decry the amount of money spent on research support. [Blum, 1988], for example, cited the skyrocketing costs associated with recruiting faculty researchers in the sciences and in engineering. Equipment and lab facilities may have to be purchased to be successful in recruiting strong researchers. [Byrne, 1990] said that "hundreds of millions of dollars are spent annually on research by business-school faculty, and critics say that professors are spending far too much time on fuzzy academic theories in narrowly defined disciplines." [Barry, 1997/1998] cites increased research at universities as one of the major factors increasing education costs.

Another criticism of the bent toward scholarly activity is that it does little to enhance classroom teaching [Lagowski, 1992; Rotton 1990]. Most educators are familiar with the call for the shift in faculty reward structures espoused by [Boyer, 1990]. He contends that reward structures are too heavily weighted toward scholarly activity and that excellence in teaching must also be rewarded. Additionally, new ways for evaluating scholarly output should be devised. [Tanner, Manakyan, and Hotard, 1992] surveyed management faculty on the notion of the relationship between teaching and scholarly activity. They conclude, "...teaching and research productivity are independent, an idea that many faculty intuitively contend."

However, scholarly research continues to be paramount at many institutions for several reasons. [Leslie and Harvey, 1998] found that many academic officers continue to believe that academic research enhances teaching. Research productivity is frequently of greater import than teaching in establishing an institution's reputation and is an element in the program accreditation process.

This study seeks to examine the support received by business school faculty for their research agendas and to uncover any potential resource-related barriers to motivation and productivity. Business school faculty members at AACSB-accredited institutions are surveyed for their perceptions of research support at their institutions.

\section{Survey Design}

Survey questions focus on the availability of specific types of university/college resources for research. Specific areas studied include access to computer equipment and associated databases, software, Internet services, clerical support, library, travel, release time, sabbaticals, and training/faculty development.

A list of all business school faculty at AACSB accredited institutions was compiled by combining the names found in the 1998 Prentice Hall books by James R. Hasselback entitled, Guide to Accounting, Economics, and Management Faculty. After duplications were eliminated, a list of 13,508 faculty members was obtained. A mailing list was developed by systematically selecting names from the complete list of faculty at AACSB accredited institutions. One faculty name was selected at random and then every 15 th name was added to the list. This process resulted in the mailing of 900 surveys. Surveys were anonymous and a cover letter attached to the questionnaire indicated answers would remain in the strictest confidence. Survey recipients were further reassured that confidentiality would not be compromised by omitting any coding on the questionnaire. These actions are intended to reduce the probability of deliberate falsification of answers.

\section{Survey Results}

Two hundred thirty one responses were received, resulting in a $25.7 \%$ response rate. This is $1.71 \%$ of the entire business school faculty at AACSB accredited institutions in the United States. Surprisingly, all respondents answered all questions. Thus, more than one fourth of faculty receiving the survey instrument provided input on this issue - a rather strong response rate for a single mailing.

A comparison of sample characteristics with those of the population indicates that some bias might be present in the sample. Full professors and those at regional universities appear to be over-represented in the sample compared to their proportions in the population. Only those faculty members who claim to be actively engaged in research are included in the analysis. 
The possibility of non-response bias must also be considered. Do those faculty members who completed the questionnaire feel the same way as those who did not? It is impossible to be certain. Speculation might suggest that those who are currently dissatisfied with research support may be more likely to complete the questionnaire as a means of expressing their displeasure. At the same time, satisfied faculty members might be less likely to do so. As mentioned earlier, coding was omitted due to the sensitive nature of these issues, thereby eliminating the chance for follow-up with non-respondents. Similar problems exist in most survey-based research. However, the results in this paper should allow academic administrators to identify those areas where resource inadequacies appear to be particularly acute and which could have detrimental effects on the ability of business school faculty to demonstrate their research productivity.

Respondent characteristics can be summarized as follows. Of the 222 persons indicating institutional affiliation, 115 or $51.8 \%$ were from national universities. From that same group, 76 or $34.2 \%$ were from public universities, while 39 or $17.6 \%$ were affiliated with private universities. Responses were received from 87 faculty members at regional public universities $(37.1 \%)$, while just 20 or $9 \%$ were from regional private universities. The corresponding population figures are 9,071 (71.6\%) from national universities and 3,593 (28.4\%) from regional institutions. The sample contained 24 assistant professors (10.4\%), 60 associate professors (26\%), and 141 full professors $(61 \%)$. The ranking among all business school faculty is distributed as follows $4,259(31.7 \%)$ are assistant professors or instructors; 3,850 are associate professors (28.5\%); while 5,399 (40\%) are full professors. A stratified proportional sample was not obtained as faculty members at regional institutions and full professors are over-represented relative to the population. This may be due to auspices bias. Therefore, demographic analysis of results will be only suggestive rather than definitive.

The proportion of respondents classifying research support as of "good or excellent quality" for ten different resource categories, both overall and by type of institution is reported in Table 1. Chi-square difference of proportion tests are used in the analysis because the research question is dichotomous - is the level of research support adequate? Table 2 reports on the relationship between various levels of research support and institutional type. Resource availability is found to vary by type of institution for three of the ten categories.

Since the wording of particular questions may influence individual responses, the reader may wish to refer to the questionnaire in the Appendix. Respondents were directed to "Please circle the appropriate response to indicate the level of support you receive in each of the following areas in pursuing your research agenda." The respondent was asked to "Use the following categories in responding to each of the items below. ( $0=$ Not Important; 1= Not Available; 2=Minimal or Poor Quality; 3=Adequate or Acceptable Quality; 4=Good Quality; 5=Excellent Quality)."

\section{Categories Where Research Support Is Adequate}

A majority of faculty members reported research support to be "good or excellent" in four of the ten categories examined. They include Internet access, computer equipment, software, and databases.

\subsection{Internet Access And Computer Equipment}

Access to the Internet among business school faculty is very widespread. More than 78 percent of those responding to the survey rate Internet access as "good or excellent". Just 5.7 percent rate the quality as poor. Only 0.4 percent reports that Internet access is not important in their research.

Internet access is nearly ubiquitous at national public universities. Eighty nine percent of faculty at those institutions indicate quality is "good or excellent," while three-fourths of professors at the other three types of schools have the same feelings about the quality of Internet access. Chi-square test results confirm that the proportion of faculty rating Internet access as "good or excellent" is significantly higher at national public universities.

More than 70 percent of the respondents rate the quality of computer equipment as "good or excellent." Satisfaction does not vary by type of school. 
Table 1

Proportion of Respondents Stating Availability of Research Input Is “Good or Excellent,"Overall and by Type of Institution

\begin{tabular}{|c|c|c|c|c|c|c|}
\hline \multirow[b]{3}{*}{ Item Number } & \multirow[b]{3}{*}{ Resource Input } & \multirow[b]{3}{*}{ Overall \% } & \multicolumn{4}{|c|}{ Percentage by Type of Institution } \\
\hline & & & \multicolumn{2}{|c|}{ National } & \multicolumn{2}{|c|}{ Regional } \\
\hline & & & Public & Private & Public & Private \\
\hline 1 & Computer Equipment & 70.6 & 74.7 & 68.4 & 72.4 & 66.7 \\
\hline 2 & Research Database & 52.0 & 64.7 & 66.7 & 47.0 & 47.4 \\
\hline 3 & Software & 59.6 & 60.0 & 60.5 & 57.5 & 57.1 \\
\hline 4 & Internet & 78.5 & 89.0 & 71.8 & 74.7 & 71.4 \\
\hline 5 & Clerical & 33.0 & 31.6 & 41.0 & 33.3 & 20.0 \\
\hline 6 & Library & 43.7 & 46.0 & 59.0 & 33.0 & 40.0 \\
\hline 7 & Travel & 29.2 & 28.9 & 44.7 & 18.4 & 42.9 \\
\hline 8 & Release Time & 19.1 & 24.0 & 25.6 & 10.5 & 19.0 \\
\hline 9 & Sabbaticals & 34.0 & 39.2 & 44.7 & 25.0 & 40.0 \\
\hline 10 & Tr./Faculty Develop & 20.5 & 23.6 & 24.3 & 18.1 & 20.0 \\
\hline
\end{tabular}

Table 2

Chi Square Difference of Proportion Tests by Type of Institution

\begin{tabular}{|c|l|c|c|}
\hline Item Number & Resource Input & $\begin{array}{c}\text { Chi Square } \\
\text { Value }\end{array}$ & P-Value \\
\hline 1 & Computer Equipment & 6.025 & 0.420 \\
\hline 2 & Research Database & 12.577 & 0.183 \\
\hline 3 & Software & 8.376 & 0.497 \\
\hline 4 & Internet & 14.156 & $0.028 * *$ \\
\hline 5 & Clerical & 7.655 & 0.569 \\
\hline 6 & Library & 16.781 & $0.052^{*}$ \\
\hline 7 & Travel & 32.320 & $0.0001 * * *$ \\
\hline 8 & Release Time & 6.652 & 0.354 \\
\hline 9 & Sabbaticals & 9.227 & 0.161 \\
\hline 10 & Tr./Faculty Develop & 1.852 & 0.933 \\
\hline
\end{tabular}

Notes:

*Significant at alpha $=0.10$

$* *$ Significant at alpha $=0.05$

$* * *$ Significant at alpha $=0.01$

\subsection{Software And Research Databases}

Six of ten survey respondents report the quality of available software as "good or excellent," while one in ten indicate that software is either "not available or of poor quality." The chi-square tests indicate no significant differences by type of institution.

A majority of survey respondents (52\%) feel that support for research databases was "good or excellent." On the other hand, one in six faculty members (16.3\%) desiring to use databases in their research state that such materials are either "not available or of poor quality." While the sample statistics seem to indicate some decline in the level of support for research databases at regional universities, chi-square results find no statistically significant difference in satisfaction with the quality of research database availability by type of school. 


\section{Categories Where Inadequate Research Support Exists}

Less than half of the respondents rate the other six research-related resource categories as "good" or "excellent." These areas include libraries, sabbaticals, clerical support, travel, training/faculty development, and the availability of release time. These are categories that faculty feel can be strengthened if the goal is to encourage more research.

\subsection{Library}

While all faculty members indicate that the quality of the library is an important input in enabling them to conduct research, less than half of the respondents (43.7\%) rate their library as "good or excellent." Even more troubling, nearly one in five (19.7\%) said their libraries are either "not available or of poor quality."

The range of responses varies widely by type of institution. Just one in three faculty at regional public institutions claim the library at their school is "good or excellent." At the other extreme, $59 \%$ of professors at national private universities perceive their libraries to be that strong. Only four in ten faculty members at national public and regional private colleges feel the libraries at their schools are "good or excellent." The chi-square value is significant with nearly $95 \%$ confidence. These figures suggest that while library facilities are less than outstanding at all business colleges, they may be particularly weak at regional institutions.

\subsection{Sabbaticals, Clerical Support, And Travel}

Only about one-third of the respondents give a "good or excellent" rating to their institution's support for these three categories. These areas deserve additional attention in attempting to increase faculty research productivity.

An overwhelming number of faculty respondents feel sabbaticals are important in conducting their research, while just one in three or 34\% classify their access to this benefit as "good or excellent." Sabbaticals are unavailable to one of eight (12.7\%) professors completing the survey. This indicates that sabbaticals are the least available research input to business school faculty. Among those with sabbatical opportunities, an additional 17.9\% indicated availability is "poor." In summary, three of ten faculty members state that sabbaticals are either "not available" or access is "poor."

Nearly $99 \%$ of the survey respondents reported that the quality of clerical support is important in conducting their research. Of those valuing clerical support, 7.4\% said it is "not available" at their institution. An additional $27.8 \%$ claim the quality of clerical support is "poor." Combining these responses, over $35 \%$ of professors find clerical assistance to be either "not available or poor." On the other hand, just 33\% indicate clerical assistance for research is "good or excellent."

Just about three in ten respondents (29.2\%) state resources for travel are either "good or excellent." Nearly four of ten (38.9\%), claim travel access is either "not available or poor." In addition, all respondents said that the ability to travel is very important to their research agendas.

The type of institution is highly related to availability of resources for travel. The differences are striking! Faculty members at private universities, whether national or regional, enjoy very high levels of support for travel. Between 43 and $45 \%$ of those at private schools rate their travel resources as "good or excellent." A mere 18\% of faculty members at regional public universities rate the travel budget as "good or excellent." These differences between private and public schools travel-related resources are significant with $99.9 \%$ confidence.

Travel to professional meetings is particularly important for young professors or those with weak publication records. Contacts established at such meetings can provide opportunities for future research collaboration or for meeting journal editors who might be interested in publishing their works. 


\subsection{Training And Faculty Development, And Release Time}

Faculty members express the least satisfaction with resources for training and faculty development, and release time for research. Just one in five respondents classify existing resources in these areas as "good or excellent." This extremely low satisfaction level suggests that these categories might be the source of significant barriers to conducting academic research. Devoting increased emphasis and/or resources to these categories could lead to increased faculty research productivity.

Almost $10 \%$ of faculty members claim that training and development resources are unavailable at their institutions. Only one in five $(20.5 \%)$ found the current level of programs or assistance offered to be "good or excellent." Twice as many, 40.6\%, said such assistance is either "not available" or of "poor" quality. Resources for training and development are rated poorly across all types of institutions.

Many institutions claim that release time from teaching can be arranged if one is engaged in sufficient research activity or has obtained a research grant. Such a claim might be questioned based on instructor's responses to this issue. The availability of release time for research is the lowest rated factor on the survey. One of eight instructors (12.6\%) indicated that release time is "not available" at their institutions, while an additional $36.5 \%$ categorized access to release time as "poor." Combining these responses, almost half of the faculty rate this item very poorly. A mere $19 \%$ of those answering this question claim support to be "good or excellent" at their institution. Access to release time does vary by type of institution.

\section{Summary And Policy Implications}

As stated in the introduction, teaching and research are both important components of a successful faculty career in a business school at a national or regional university. Arguments continue to rage as to whether teaching and research responsibilities tend to be complementary or contradictory. However, it is safe to assume that without sufficient research productivity at most institutions, the teaching career may not continue. The requirement to "publish or perish" creates significant stress on many business school faculties. A lack of resources to support research can produce frustration and burn out among many that are strong teachers.

University administrators are to be commended for their assistance to faculty by providing quality resources for research in the areas of Internet access, computer hardware, computer software, and research databases. Between 52 and 78 percent of survey respondents rate support in these categories as "good or excellent." Adequate support for research appears to exist in these groupings.

The other six categories are rated "good or excellent" by just 20 to $44 \%$ of the respondents. The proportions ranking these factors as "good or excellent" range from about $40 \%$ for libraries, to $30 \%$ for sabbaticals, clerical help, and travel, to $20 \%$ for training/faculty development and release time. These figures suggest the need for more investigation in these areas to ascertain whether they can be limiting factors for faculty who are striving to conduct academic research.

Since academic access to the Internet has become rather ubiquitous within the past couple of years, this significant difference by type of institution can probably be ignored. Two other resource categories that are rated differently by type of institution merit attention. Library quality is rated most favorably at national private universities, while significant dissatisfaction is present at regional universities. This finding implies that the quality of business related library holdings at regional public universities might require some strengthening. Faculty members at private universities also rate their travel support much higher than those at regional public institutions. Those younger faculty members at regional institutions are likely to be impacted the most by this disparity. 


\section{Appendix \\ Survey Of Business Research Issues}

\section{Availability of University/College Resources}

Please circle the appropriate number to indicate the level of support you receive from your institution in each of the following areas in pursuing your research agenda. Use the appropriate categories in responding to each of the items below.

$0=$ Not Important

$1=$ Not Available

2=Minimal or Poor Quality

$3=$ Adequate or Acceptable

4=Good Quality

5=Excellent Quality

\begin{tabular}{|l|c|c|c|c|c|c|}
\hline Types of Research Support & Not Imp. & Not Avail & Poor & Adeq. & Good & Exc. \\
\hline Computer equipment (Hardware) & 0 & 1 & 2 & 3 & 4 & 5 \\
\hline Research data bases & 0 & 1 & 2 & 3 & 4 & 5 \\
\hline Software (other than research data bases) & 0 & 1 & 2 & 3 & 4 & 5 \\
\hline Other IT (Internet) & 0 & 1 & 2 & 3 & 4 & 5 \\
\hline Clerical assistance & 0 & 1 & 2 & 3 & 4 & 5 \\
\hline Library facilities & 0 & 1 & 2 & 3 & 4 & 5 \\
\hline Travel support & 0 & 1 & 2 & 3 & 4 & 5 \\
\hline Release Time & 0 & 1 & 2 & 3 & 4 & 5 \\
\hline Sabbaticals & 0 & 1 & 2 & 3 & 4 & 5 \\
\hline Training/faculty development & 0 & 1 & 2 & 3 & 4 & 5 \\
\hline
\end{tabular}

\section{Personal Profile}

Please provide us with some general information about yourself.

1. At what type of institution are you employed?

National University-Public Regional University-Public

National University-Private Regional University-Private

2. What is your current academic rank?
Assistant Professor Associate Professor
Professor Ranks Not Used

3. In what subject area do you do most of your teaching?
Accounting
Business Law
Economics
Finance
Management
Marketing

4. How many years has it been since you received your doctorate?
$0-6$ years
6-10 years
More than 10 year

5. How many years have you been at your present institution?

$$
0-6 \text { years 6-10 years More than } 10 \text { years }
$$

6. How many years have you been in higher education?
$0-6$ years
6-10 years
More than 10 years

7. How would you rate your graduate school experience in preparing you to meet your institutions research expectations?
Poor
Fair
Good
Excellent 


\section{References}

1. Anonymous, "Research-Intensive vs. Teaching-Intensive Institutions," Change, (May, 1991).

2. Barry, John S., "Rigging the Price for Higher Education," Academic Questions, (Winter, 1997-98).

3. Blum, Debra E., "Cost of Recruiting Researchers Soars as Equipment Becomes More Sophisticated and Competition Grows," The Chronicle of Higher Education, (Oct 5, 1998).

4. Knaub, Patricia K., \& Lee, Cheryl L., \& Meredith, William, "Prolific Family Scholars: Environmental Factors Contributing to Their Productivity," Journal of Family and Consumer Sciences, (Spring, 1995).

5. Kraemer, Kenneth L, \& Perry, James L, "Institutional Requirement for Academic Research," Public Administration Review, (Jan/Feb, 1989).

6. Leslie, Paul L., \& Harvey, Lynn K., \& Leslie, George J., "Chief Academic Officer' Perception of the Relationship Between Faculty Research and Undergraduate Teaching," Sociological Spectrum, (April-June, 1998).

7. Tanner, John R, \& Manakyan, Herman, \& Hotard, Daniel G, "Management-Faculty Research Productivity and Perceived Teaching Effectiveness," Journal of Education for Business (May/June, 1992).

8. Tien, Flora F., \& Blackburn, Robert T., "Faculty Rank System, Research Motivation, and Facutly Research Productivity, Measure Refinement and Theory Testing," The Journal of Higher Education, (Jan/Feb, 1996).

9. Van Auben, Stuart, \& Cotton, Chester C., \& McKenna, John, "Business Research: Perspectives of Deans of AACSB Accredited Business School," Journal of Education for Business, Vol. 68 Number 5, (May/June, 1993), 261-144. 